\title{
A Novel High-Performance Ti/ATONPs-MWCNTs Electrode Based on Screen Printing Technique for Degradation of C.I. Acid Red 73
}

\author{
Qiutong Xu, Xiaoliang, Song and $\mathrm{Li} \mathrm{Xu}^{*}$
}

School of Chemical Engineering and Technology, Tianjin Key Laboratory of Membrane Science and Desalination Technology, Tianjin University, Tianjin 300072, P. R. China

*E-mail: xuli620@163.com

doi: $10.20964 / 2018.01 .06$

Received: 15 August 2017 / Accepted: 5 October 2017 / Online Published: 1 December 2017

\begin{abstract}
A large effective surface area and a good electrical conductivity are very important characteristics for electrodes used in wastewater treatment. To improve them while lowering the cost, a novel MWCNTsmodified (Ti/ATONPs-MWCNTs) electrode was produced by a screen-printing technique. To test its performance, the electrode was compared to two other electrodes, namely, $\mathrm{Ti} / \mathrm{SnO}_{2}-\mathrm{Sb}$ and Ti/ATONPs. Several important electrochemical measurements including impedance spectroscopy (EIS), cyclic voltammetry (CV), chronocoulometry (CC) and linear sweep voltammetry (LSV), were used in this study. A toxic organic dye (C.I. Acid Red 73) was chosen as the target pollutant to test the degradation by the removal of chroma and chemical oxygen demand (COD). Compared to $\mathrm{Ti} / \mathrm{SnO}{ }_{2}-\mathrm{Sb}$ and Ti/ATONPs, Ti/ATONPs-MWCNTs show the lowest charge transfer resistance $(0.24 \Omega)$, the largest effective surface area $\left(61.97 \mathrm{~cm}^{2} \cdot \mathrm{cm}^{-2}\right)$ and the highest oxygen evolution potential $(2.15 \mathrm{~V})$. It is known that superior values of these performance characteristics are very important for improving the efficiency of wastewater decontamination. After $90 \mathrm{~min}$ electrolysis using Ti/ATONPs-MWCNTs, the removal of AR 73 reached $59.4 \%$, while the energy consumption was as low as only $6.2 \mathrm{Wh} \cdot \mathrm{L}^{-1}$. The remnant COD was only $45 \%$ after $3 \mathrm{~h}$ of degradation, with an instantaneous current efficiency (ICE) over $80 \%$ obtained for Ti/ATONPs-MWCNTs. These results demonstrate the promising prospects for the use of the novel Ti/ATONPs-MWCNTs electrodes in wastewater treatment processes.
\end{abstract}

Keywords: Adsorption-electrocatalysis, ATO nanoparticles, Multi-walls carbon nanotubes, Screen printing, Azo dyes

\section{$\underline{\text { FULL TEXT }}$}

(C) 2018 The Authors. Published by ESG (www.electrochemsci.org). This article is an open access article distributed under the terms and conditions of the Creative Commons Attribution license (http://creativecommons.org/licenses/by/4.0/). 